\title{
The importance of 'goodness of fit' between organizational culture and climate in the management of change: a case study in the development of online learning
}

\author{
Donald W. McMurray \\ Southern Cross University, Australia \\ email:dmcmurra@scu.edu.au
}

This paper explores the nexus between organizational culture and organizational climate in the management of change by presenting a case study wherein an Australian regional university is currently undertaking the development of online courses. Important consideration is given to the complementary roles of culture and climate in managing organizational change. The single most important determinant of success is strong, committed senior management whose task is to articulate the organization's new vision and the manner in which it reshapes the organization's culture. At another level the climate of the organization as reflected in the systems that facilitate people's work (including policies, procedures, rewards and communication) must mesh with the new culture if organizational change is to proceed smoothly. This paper discusses the interactive nature of these two powerful organizational variables. The case study draws on the experiences of a school of academics acting as developers and deliverers of online initiatives and a number of concerns are raised that threaten the goodness of fit between the culture and climate of the organization. Policy issues requisite to the successful delivery of online courses are identified and discussed. The most contentious issue revolves around the question of ownership. Many academics, accustomed to exercising autonomy with respect to determining appropriate learning strategies, openly resisted the role the Information Technology department of the university assumed in making decisions that are often seen as having pedagogical overtones. To the extent that transactional issues such as these detract from the climate of the organization, they prevent academics from performing to their full potential. It is concluded that the climate of the organization, if properly managed, contributes to an enduring organizational culture which in turn is better able to deal with the inevitability of change and face the challenges that initiatives such as online education bring. 


\section{Introduction}

The National Education Association in the USA in a recently released report entitled 'Quality on the line' (National Education Association, 2000) identified twenty-four quality measures as being essential to ensuring excellence in Internet-based learning. While establishing best practice benchmarks for the provision of quality online distance education, the report does not fully address important policy issues in relation to the role of technology in the selection of appropriate teaching and learning strategies. Furthermore, it does not address the important question of the management of organizational change in today's higher education environment. This paper explores the nexus between organizational culture and organizational climate in the management of change process by presenting a case study of an Australian regional university currently undertaking the development of online courses.

\section{Change}

Theobold (1997) suggests, in his last book Reworking Success, that we are continually being confronted with major challenges which require profound changes in every aspect of our lives. Organizational leaders talk about 'turbulent times' and 'discontinuous times', where we face a future that is essentially unknowable (Stacey, 1992). No longer do linear models of cause-effect apply, if they ever did. Management cannot afford the luxury of adopting a reactive stance in the face of forces of change that are emanating from within or, alternatively, looming over the horizon.

The management of change is perhaps the most daunting challenge facing senior managers in organizations today. During times of change there are at least two camps, those wanting to implement the change and those who feel they will suffer under the change. The latter group views managers as 'inflictors of change'. Both groups are motivated differently, one by the desire to move forward and the other by the understandable desire to remain within the safe and comfortable status quo. Many simply throw up their hands in despair complaining of symptoms of 'change fatigue'. There are times, however, when organizational members are genuinely excited by the challenge of confronting the unknown. Hence, the dynamic interaction between the desire for security and change is always with us.

\section{Technology and change management}

Organizations need to scan the environment continuously in an attempt to detect the winds of change and move quickly and proactively to position themselves in anticipation of those change forces. Of all the drivers, technology has brought about the most radical change. A third industrial revolution has occurred within the manufacturing industry with the advent of computer-integrated systems. Here robotics have all but replaced the assembly-line worker as the pace of automation is stepped up. It is argued below that the same fate potentially awaits academics as they are thrust increasingly into the role of knowledge workers. Elsewhere, microelectronics and fibre optics have turned the information and communication industries upside down. Nowhere is this more true than in universities where technological determinism is rife today. The availability of this new technology together with the force of economic pressures, owing to changes in national and international markets, makes it imperative for organizations to anticipate and manage the 
forces of change if they wish to survive. Yet the manner in which they are taking up the challenge is threatening the very foundations of the traditional university (Coady, 2000).

\section{The role of culture and climate in managing change}

It was commonplace in the 1980 s and 1990 s for change agents to focus their efforts on reshaping the existing culture as a mechanism for accommodating change. Organizational change came to be seen as synonymous with cultural change (Bate, 1995; Deal and Kennedy, 1982; Legge, 1994). What follows is a brief discussion of culture and its relationship with its twin concept climate.

- Organizational culture embraces shared assumptions, including beliefs and values, that determine what needs doing and how it can be done. Key values and beliefs of an organization most often are embodied in the language of memos, reports or policy statements and reflect a number of recurring elements including widely shared values (e.g. the customer comes first) which are often implicit and almost taken for granted (Kabanoff, 1993). Because change is occurring in an increasingly complex and rapid manner the strategy of reshaping the existing culture is no longer workable. Culture changes slowly in spite of the efforts of management to accelerate the process for, as Fullan so aptly put it, you cannot mandate what matters (Fullan, 1993). Instead, leaders of change-focused cultures have turned their attention to the management of organizational climate. Ashforth (1985) claims that organizational climate is an empiricist substitute for the richer term culture, which

- embodies members' collective perceptions about their organization with respect to such dimensions as autonomy, trust, cohesiveness, support, recognition, innovation and fairness;

- is produced by member interaction;

- serves as a basis for interpreting the situation; and

- reflects the prevalent norms, values and attitudes of the organization's culture.

(Moran and Volkwein, 1992: 20)

Simply put, organizational climate is a by-product of naturally occurring interactions between people and is reflected in all of the following:

- levels of stress;

- the extent to which people are treated fairly;

- the ways in which decisions are made;

- the sharing of power;

- the management of information;

- mechanisms for recognizing individual excellence; and

- empowerment processes that enable people to do their jobs autonomously.

Thus it can be seen that these twin organizational variables share a number of overlapping attributes and while it is conceded that the concepts of culture and climate are not co- 
extensive, some authors (Turnipseed, 1988) claim it is not a large conceptual step from shared assumptions (culture) to shared perceptions (climate). There needs to be a recognition that climate, as well as being influenced by culture, is simultaneously capable of shaping culture. Where there is non-alignment of culture and climate the likelihood of successful organizational change is diminished.

To summarize, organizational members develop shared perceptions of their workplace (i.e. climate) in large part against a common frame of reference (i.e. culture) that is continually created and re-created. It is strongly contended in this paper that the climate of the organization, if properly managed, will contribute to an enduring organizational culture which in turn will be better able to deal with the inevitability of change. Where elements of climate are poorly managed or not managed at all, organizational members will resist change openly.

\section{The culture of the new university in Australia}

Coady (2000) has documented the impact of some of the change forces operating on Australian universities today. Innovation, flexibility, responsiveness and the creative redefinition of markets have become the new sources of competitive advantage in an increasingly interconnected global economy (Dess and Picken, 2000). Amongst higher education managers the quest is under way to find ways of attracting and maintaining enrolments from a dwindling pool of students. The drive for increased efficiency has been underway for a number of years now as government funding continues to shrink and universities redirect their energies towards a new constituency, that of the full fee-paying student. In the last eight years money from full fee-paying students has trebled from $\$ 500$ million to $\$ 1.5$ billion (Way, 2000). In this new corporate environment, however, the payment of fees redefines the student as customer and in the interests of customer satisfaction there has been a subtle shift for the responsibility for learning from the student to the academic (Kenway and Langmead, 1998).

The application of business management principles to the running of the university has been accompanied by stricter controls, greater work pressures, more clearly defined jobs, tighter supervision and the introduction of performance appraisals. It is clear that these regressive measures have just about run their course in terms of their ability to provide tertiary education institutions with efficiency gains. Now, out of a sense of urgency, management is turning to other initiatives as a way of securing new markets. Prominent amongst these is online learning and the accompanying claim that technology-driven education is the key to vastly improved learning. A more cynical view is that online education serves the aggregated interests of rationalization, corporatization and marketization (Kenway and Langmead, 1998). A careful reading of the Review of Higher Education Financing Policy (West, 1998) points to a hyper-rationalist view that the introduction of new technology will bring about a cost reduction in higher education.

\section{The online experience at a small regional university}

In 1998 the executive of a small regional university in the north-east of New South Wales, funded two significant projects in two schools. The joint venture involved the application of project management methodology to the development and delivery of a suite of online units within these schools (Phelps, Ledgerwood, and Bartlett, 2000). 
It is not the intention of this paper to detail these initiatives as these projects have been discussed in several articles to date (Ellis, forthcoming; Ellis and Phelps, 2000; Klich, Fitzgerald and Wallace, 1999; McMurray and Dunlop, 2000). This paper addresses the broader issues arising out of the project in one of the schools and specifically is concerned with technological, administrative, instructional and academic matters surrounding the online delivery of education. An attempt will be made to assess the impact of these issues on the twin organizational variables of culture and climate in a university in the process of large-scale change.

The allocation of funding to these two projects was made contingent upon the establishment of two project management boards which assumed control of all planning, organizing and reporting functions. As noted by Phelps et al. (2000) academic course development in universities has not often occurred within a project management framework. Formal structures for responsibility and accountability do not sit well with academics, who are accustomed to operating autonomously or as part of a small collegial team. For both projects online delivery was to involve more than simply 'Web mounting' the content of print-based off-campus units. They specifically set out to explore whether Web-based units could be seen as a tool to enhance student learning outcomes and not just a medium for delivery. The focus was to be on putting students in contact with other students and not simply connecting them to a vast database where interactivity is reduced to a series of mouse clicks and the teacher is all but non-existent (Green, 1999).

The employment of project management methodology to develop the online initiative created tensions from the beginning that were to affect both the climate and culture of the organization. Academics clashed openly with senior managers on the project management board over what one side viewed as issues relating to academic freedom, and the other side saw as issues concerning the shift towards managerialism within the university.

Clearly management was preoccupied with the online project as a product to be marketed to a range of clients, including overseas students, whereas the academic developers were more process-orientated as they set about enhancing teaching and learning in a new and exciting medium (Phelps et al., 2000). Academics were strongly of the view that learning experiences need to be structured on sound pedagogy and not simply be a showcase for the latest platform used to promote online learning. Management, on the other hand, seemed to have adopted the belief that future educational outcomes are guaranteed by technological progress and that this in turn will lead to the best of all possible worlds (social progress). What in fact happened is that the interests of the powerful were being enacted under the guise of social progress. Academics were relegated to the role of 'knowledge workers' whose primary task, it seemed, was to connect clients with information (Heron, 1996), while at the same time power flowed increasingly to the upper echelons of the university to those who managed and marketed that knowledge. It is contended strongly that knowledge cannot be managed separately from those people who have formulated the intellectual basis to that knowledge.

It was one thing for academics to hand over the responsibility for the 'look and feel' of the units to the Information Technology Directorate, but another thing entirely when important decisions about the choice of delivery shell and supporting software were made without consultation, involvement or debate. A decision was made to adopt an off-the- 
shelf commercial product rather than custom write course software. Accordingly, the University entered into an agreement with a large computer corporation to acquire the use of one of its platforms as a delivery shell. The software could also be used in conjunction with a browser. The decision to proceed with the shell was made despite the growing conviction from the majority of the academic staff developers that it would prove to be inordinately difficult for students to cope with. As the initial evaluation (Hayden, Saenger and Parry, 1999) showed, staff concerns were justified. While many staff had found the shell relatively easy to develop their online materials within, it became problematic in the hands of students in remote areas without the level of technological support the staff had enjoyed during the development phase. Ultimately for online education to succeed it must meet the needs of the end-user independently of any advantages that might accrue to the academic developer along the way (Griffiths, 2000).

Many academics, accustomed to exercising autonomy with respect to developing and delivering learning materials, openly resisted the role the Information Technology Directorate of the University assumed in making decisions that often were seen as having pedagogical overtones (McMurray and Dunlop, 2000). For example, changes were made to the content of units without prior consultation with or notification to the academic responsible for the development of the online unit. On another occasion an academic was advised that a unit he had developed and delivered to distance education students in Australia was to be offered in its existing format offshore. When reservations were expressed regarding the cultural relevance of some of the content the academic was informed that if he did not agree to teach the course they (the Information Technology Directorate) would find someone who would. As Passmore (2000) notes these kinds of decisions raise serious questions about the topic of intellectual property in terms of who owns and controls the products and the processes of online initiatives. Green (1999) questions whether educational technologists are there to support and assist knowledge workers in the tertiary sector or is the ultimate goal to replace them? Are our leaders dreaming of teacherless education? And what then are the pedagogical implications of a technology-orientated knowledge base?

There is little doubt that the most precious relationship in a university is the one between the academic teachers and their students (Manne, 2000). It is understandable, therefore, that online deliverers within the school, when asked to provide management with unrestricted access to the online units, reacted strongly in defence of what they saw as an invasion of students' privacy. For their troubles they were castigated for presuming to institute policy that would have institution-wide ramifications. Academics held fast to the notion that opening up the units to scrutiny from above would constitute an unwarranted intrusion into the communication relationships the students had established with their instructor and with each other.

The manner in which these decisions were taken was interpreted by some staff as signalling a shift in university governmentality from one of supporting a culture of teaching, learning and research to one which is setting off down a path of hyper-competitiveness where corporatization and globalization become the driving forces (Kenway and Langmead, 1998) and where academic autonomy is threatened.

On another level the tensions between the academics and the project management board can be better understood as being the product of the lack of alignment between the 
organizational culture and climate of sections of the university. As mentioned earlier, these two concepts are inextricably intertwined and it is clear that university policy as reflected in management decisions served to undermine an otherwise healthy school climate. Superimposing a project management structure over online development was tantamount. to overwriting a stable subclimate of the organization with an organizational culture that was attempting to shift too far, too quickly and in an unwelcome direction (Hayden et al., 1999).

There had been consultation at the university over the development of the online initiative but it had for the most part involved communicating information about decisions which had already been made by senior management within the university. A case in point involved the adoption of Learning Space as the delivery shell. At a special meeting called in good faith by the Head of School towards the end of the developmental phase, and prior to the initial delivery of the online units, concerned academics spent two hours voicing their concerns over what they saw as problematic with this delivery shell. Later, it was learned that a contract binding the university to the supplier for a period of three years had already been signed at higher management levels. The suppression of open dialogue caused unnecessary staff angst.

While the literature is replete with examples of how this top-down 'command and control' style of management can inhibit organizational learning, somehow management ploughed ahead. As it turned out the worst fears of the academics were realized. In their initial evaluation, Hayden et al. (1999) reported that the successful rate of completion for the school's online units was just 58 per cent compared with almost 90 per cent for both conventional distance education and face-to-face enrolments. Further, the chief reason cited for the large attrition rate was the frustration associated with installing and navigating within the chosen platform. The learning curve at the front end was simply too steep for many students who gave up in despair and reverted to the traditional external mode of study.

The above examples underline the fact that we have witnessed the demise of one of the most time-honoured structures of the university - that of the collective decision-making structure known as collegiality. Collegiality and academic freedom count for little in the eyes of the managers of the business enterprise as they compete openly with other universities for limited government funding and market. True collegiality does not involve talking about things in general, nor entering into mere dialogue but involves open-minded consideration of all the issues involved and reaching a consensus, through an increase in synergy, not by accepting the lowest common denominator (Coady, 2000).

\section{Are universities learning organizations?}

Upon reflection, given that our masters were determined to take the university down this hyper-competitive road, surely it was incumbent upon them to do so by utilizing the best available knowledge on how best to proceed. The literature surrounding the emergence of the learning organization would have been a good place to begin (Argyris and Schon, 1996; Grieves, 2000; Hase, 1998; and Senge, 1990). There they would have discovered the folly of attempting to mandate change in a top-down fashion by re-engineering the existing culture (Legge, 1994). 
Most universities are still hierarchically structured with clearly defined lines of authority, responsibility and control. Yet in these rapidly changing times universities, like any learning organization, need to be flexible and adaptable to survive and grow. Interactive consultation is a common thread that runs through all the disciplines of the learning organization. This is a process of sharing thoughts and feelings through talking things out with others in an atmosphere of co-operation and openness with a commitment to accomplishing some definite, common purpose. It seems obvious that senior management at the university believe control and responsibility would be lost if employees are involved in this process.

What has resulted is a lack of 'goodness of fit' between the culture and climate of the university. The new operating systems imposed by management are at odds with the traditional worthwhile values of the university. What is called for is a basic reassessment of the value of the academic's worth to the university. Here, it is important to distinguish between 'system' and 'value' changes within the university. A system change simply encompasses changed processes or procedures. Value changes, on the other hand, run deeper. In the end, value changes arising out of new workplace relations will be the driver of organizational change. Open dialogue is needed around worthwhile change as opposed to imposed change.

There are a number of factors contributing to a lack of 'goodness of fit' between culture and climate in the university including:

- management's use of power and authority to stifle debate;

- lack of vision and poorly communicated plans for change;

- lack of adequate resources;

- differential treatment of staff, some of whom feel isolated;

- communication barriers between staff and management; and

- conflicting personalities fuelled by differing values and ethics.

It can be seen that these elements are features of organizational climate which need to be managed carefully when people are being asked to change. Change has to be perceived by people as something happening through them and not to them. No one copes well with the feeling of 'not having been consulted'. What emerges during this phase is a new organizational culture. But this is not something that can be manipulated by a leader independently of the experiences of the followers for they are equally the carriers of the new culture and are in a position to unite or sabotage the change process.

Change of the kind associated with moving to an online environment is not a one-step process for academics, but one that sees them in transition as they let go of the old and prepare to embrace the new. A key question that needs to be asked is: 'How much of the past do they need to let go in order to embrace the future?'

In fact, this is the time for senior management to be asking questions but not the kind that give rise to a strategic plan such as the following might:

- What makes our organization unique? 
- What are the change-forces impacting on our business?

- What are the threats and what are the opportunities?

- What is it that our customers really want?

Important though these questions may be, they are premature. The following kinds of questions need to be asked:

- Why do you work here?

- What was it that originally attracted you to this organization?

- Have things changed in this regard?

- What things do you really value that you find missing in your workplace?

Of course what will be revealed are people's needs, values and beliefs. Aggregated together they represent members' perceptions about the climate of the organization and the way in which it operates. Once defined, these values and beliefs will serve as a series of powerful rudders that will assist in navigating the turbulent waters of change. In the final analysis the message is quite simple: manage the climate and the culture will look after itself. In the end a new culture will emerge but it will be one that is congruent with, and a reflection of, the prevailing organizational climate.

\section{References}

Argyris, C. and Schon, D. A. (1996), Organizational Learning II: Theory, Method and Practice, Reading, MA: Addison-Wesley.

Ashforth, B. E. (1985), 'Climate formation: issues and extensions', Academy of Management Review, 10, 837-47.

Bate, P. (1995), Strategies for Cultural Change, Oxford: Butterworth-Heinemann.

Coady, T. (ed.) (2000), Why Universities Matter, Sydney: Allen and Unwin.

Deal, T. and Kennedy, A. (1982), Corporate Cultures, Reading, MA: Addison-Wesley.

Dess, G. and Picken, J. (2000), 'Changing roles: leadership in the 21st century', Organizational Dynamics, Winter, 23-6.

Ellis, A. (forthcoming), 'Instructional support for Web-based courseware development', Journal of Education and Information Technologies.

Ellis, A. and Phelps, R. (2000), 'Staff development for online delivery: a collaborative, team based action learning model', Australian Journal of Educational Technology, 16 (1), 26-44.

Fullan, M. (1993), Change Forces: Probing the Depths of Educational Reform, London: Falmer Press.

Green, M. (1999), 'Developments in online delivery', Training Agenda, 7 (2), 12-13.

Grieves, J. (2000), 'Navigating change into the new millennium: themes and issues for the learning organization', The Learning Organization, 7 (2), 54-74. 
Griffiths, A. (2000), 'ELearning: slow to take off', HR Monthly, June, 26-8.

Hase, S. (1998), 'Work-based learning for learning organizations', in J. Stephenson and M. York (eds), Capability and Quality in Higher Education, London: Kogan Page.

Hayden, M., Saenger, H. and Parry, S. (1999), An Evaluation of the Online Units delivered in First Semester 1999, Lismore: Southern Cross University.

Heron, L. (1996), 'Knowledge workers or threatened species? A commentary', Australian Universities Review, 1, 26-8.

National Education Association (2000), Quality on the Line, Higher Education Financing Policy and Review Committee, Institute for Higher Education Policy, March 2000.

Kabanoff, B. (1993), 'An exploration of espoused culture in Australian organizations (with a closer look at the banking sector', Asia Pacific Journal of Human Resources, 31 (3), Spring, 1-29.

Kenway, J. and Langmead, D. (1998), 'Governmentality, the "now" university and the future of knowledge work', Australian Universities Review, 2, 28-32.

Klich, Z., Fitzgerald, B. and Wallace, M. (1999), 'On and off (campus, line, shore): removing national organizational and learning boundaries', International Flexible Learning and Technology Conference, Monash University, 28 September.

Legge, K. (1994), 'Managing culture: fact or fiction', in K. Sisson (ed.), Personnel Management: A Comprehensive Guide to Theory and Practice in Great Britain (2nd edn), Oxford: Blackwell, 397-433.

Manne, R. (2000), 'Why universities matter', Dissent, 15-17.

McMurray, D. W. and Dunlop, M. E. (2000), 'The collaborative aspects of online learning: a pilot study', UltiBase, July, http://ultibase.rmit.edu.aulArticles/online/mcmurrayl.html.

Moran, E. T. and Volkwein, J. F. (1992), 'The cultural approach to the formation of organizational climate', Human Relations, 45 (1), 19-46.

Passmore, D. (2000), 'Impediments to adoption of Web-based course delivery (online)', http://www.itsligo.ielstafflbmulligan/web/EdTech2000.htm, [25 June].

Phelps, R., Ledgerwood, T. and Bartlett, E. (2000), 'Managing the transition to online teaching: the role of project management methodology in the Learning Organization', Moving Online Conference, Gold Coast, Australia, August.

Sackman, S. A. (1991), 'Uncovering culture in organizations', Journal of Applied Behavioral Science, 27 (3), 295-317.

Senge, P. (1990), The Fifth Discipline: The Art and Practice of the Learning Organization, New York: Doubleday.

Stacey, R. (1992), Managing the Unknowable, San Francisco: Jossey-Bass.

Theobold, R. (1997), Reworking Success: New Communities at the New Millennium, Gabriole Island, BC: New Society. 
Turnipseed, J. (1988), An integrated, interactive model of organizational climate, culture and effectiveness', Leadership and Organization, 9 (5), 17-21.

Way, N. (2000), 'Degrees for sale', http://www.brw.com.au/stories/20000728/6559.htm.

West, R. (1998), 'Learning for life: a review of higher education financing and policy: a policy discussion paper', http://www. deetya.gov.aularchivelhighered/hereview/herr.pdf. 